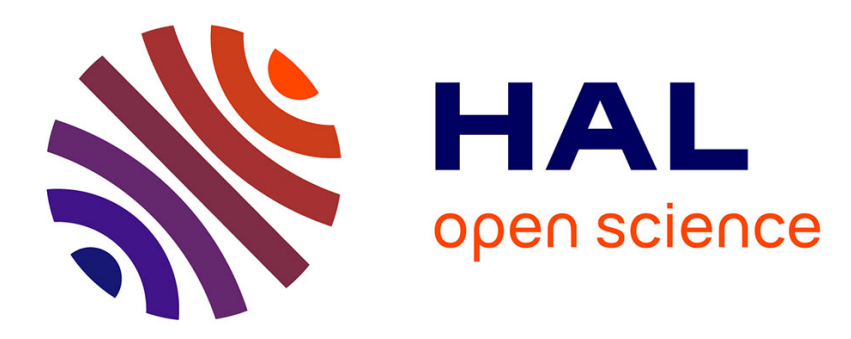

\title{
The history of the French tableau de bord (1885-1975): evidence from the archives
}

\author{
Anne Pezet
}

\section{To cite this version:}

Anne Pezet. The history of the French tableau de bord (1885-1975): evidence from the archives. Accounting Business and Financial History, 2009, 19 (2), pp.103-125. halshs-00498670

\section{HAL Id: halshs-00498670 \\ https://shs.hal.science/halshs-00498670}

Submitted on 8 Jul 2010

HAL is a multi-disciplinary open access archive for the deposit and dissemination of scientific research documents, whether they are published or not. The documents may come from teaching and research institutions in France or abroad, or from public or private research centers.
L'archive ouverte pluridisciplinaire HAL, est destinée au dépôt et à la diffusion de documents scientifiques de niveau recherche, publiés ou non, émanant des établissements d'enseignement et de recherche français ou étrangers, des laboratoires publics ou privés. 


\title{
The history of the French tableau de bord (1885-1975): evidence from the archives
}

\author{
Anne Pezet ${ }^{1}$ \\ Université Paris Dauphine, DRM, France
}

\begin{abstract}
The history of the tableau de bord in France has never really been written. This paper sets out to draw up a history using the archives of three large industrial companies - Lafarge, Pechiney, and Saint-Gobain - as source material. This paper seeks to revisit the myth of the French tableau de bord as presented in a great many comparative management studies (typically, Tableau de bord vs. Balanced Score (ard). This myth rests on more or less implicit assumptions regarding, for instance, the central role played by engineers in the emergence of tableaux de bord, the single and unified way in which this instrument is used in companies from top to bottom and, or course, its French specificity.
\end{abstract}

Keywords: French tableau de bord, scorecard, managerial innovation.

\section{Introduction}

The French-style tableau de bord is often compared or contrasted with what is commonly considered to be its American equivalent, the Balanced ScoreCard (BSC) (Bessire and Baker 2005; Bourguignon et al. 2004; Epstein and Manzoni 1997; Gray and Pesqueux 1993). These comparisons use technical, strategic, cultural or ideological criteria. However, they are founded on a 'history' of the tableau de bord that has never been carried out in accordance with the methods of historical research. The sole exception appears to be Malo (1995) who sought to retrace the history of the tableau de bord using studies from the past (notably, Satet and Voraz 1932) and using 'leads' that appeared in historical research papers not pertaining to tableaux de bord (the works of Lemarchand (1993) and Nikitin (1992)). Consequently, comparative studies - generally the fruit of collaboration between French and foreign researchers (contributing research on BSC) - are based on a history of tableaux de bord that remains largely mythical. In this regard, Lebas (1994, 1996) outlined a history ('a little history') highlighting the major roles played by the State and engineers in the emergence of management accounting and tableaux de bord in France. Unfortunately, this little history, interesting in itself, lacks references to primary sources. Even though it may be likely, intuitively speaking, that the State and engineers did play a role in this case, the elements of proof are still required. This paper's purposes are, therefore, two-fold. First, to compare the myth of the history of the tableau de bord with the reality observed in the archives; and second, to rethink the tableau de bord along the lines of a more theoretical perspective.

A fundamental issue for this research is the question of what, conceptually, constitutes a tableau de bord. Trying to unveil this, and the use made of a tableau de bord, raises the potential problem of anachronism. In this article, we have aimed to find the first appearances of what was going to subsequently identified as the French tableau de bord.

\footnotetext{
${ }^{1}$ Email: anne.pezet@dauphine.fr
} 
This quest through the archives arouses an ambiguity: if we are to discover tableaux de bord before they were conceptualized, we need to have an a priori definition. Only then can we both trace the device through the archives and conduct a reflection about its meanings.

These observations beg the question of what, in a practical sense, constitutes a tableau de bord. A survey of the main French management accounting textbooks tends to provide a broad definition: combining the normative and the cognitive approaches, we can define the French tableaux de bord as a system of indicators that aim at monitoring and conducting economic operations and individual behaviours in a way that is compatible with the business strategy. The tableau de bord is generally considered as a supplement to financial and accounting measures. It has to gather, in the same device (paper sheet, log or, today, electronic spreadsheet) quantitative and qualitative data as well as financial data. This comprehensive definition will help us to assess the historical development of the tableau de bord compared with what theorists think it should be.

However, rethinking the tableau de bord along the lines of a more theoretical perspective is a major purpose of our study. The history of the tableau de bord in France retraces the steps of industrial leaders in their quest to find a device enabling them to see and to observe companies that had moved out of sight, physically speaking. The tableau de bord is a device that associates 'representing' and 'intervening', to use the terms suggested by Hacking (1983). The tableau de bord is firstly a means of representing a reality common to any large company in which operational activities move away from the centre and become less visible. The tableau de bord is also a means of intervening because, if 'the theories force themselves to say how the world is, the experimentation and technology that stem from them change the world. We represent and we intervene' (Hacking 1983, 31). The tableau de bord combines seeing with doing. It provides the senior manager with an insight into what he can no longer physically see due to distance; and it also provides the means of intervening through the decision-making that it engenders.

The archival research revealed in this paper shows that the tableau de bord arose out of the issue of seeing and doing. In the context of the 1920s and 1930s, the tableau de bord seemed to be the answer to the changes in progress. Strong growth and a powerful movement towards concentration at the macroeconomic level converged with the emergence of certain schools of thought such as the technocracy and planisme movements (Kuisel 1984) at the macro-social level. At the meso level - the level of the corporation the period was favourable to holdings and alliances, to the creation of subsidiaries in large companies and to the weakening of centralisation (Levy-Leboyer 1980). At the micro level - the level of the manager - these phenomena raised new questions: how to control (command) these increasingly large and dispersed entities? A new mode of representing was sought, which would also change the ways of intervening.

Yet, it was at the end of the nineteenth century that leaders began to gather information through the rapport hebdomadaire, a 'weekly report', or through a journal de marche, or 'logbook'. Essentially, this information was presented in the form of a narrative. From the 1920s and 1930s onwards, the tableau de bord, before it was named as such, appears from our contemporary viewpoint as the device that senior managers had sought after. They proclaimed their need for information, for 'statistics' on sales and production. Alas, although everything seemed to suggest that the tableau de bord would finally emerge in its canonical form, the boards of the three companies studied adopted budgetary control! To borrow terms from Giddens (1990), it seems that, in the end, a 'modern global expert knowledge system', i.e. budgetary control, had gained the upper hand over the 'local process knowledge' that would have been the tableau de bord. The senior manager's tableau de bord would not take 'definitive' shape until the 1950s. This is 
not to mention the rapid changes which it underwent at that time towards more financial data, significantly altering the model that is presented in today's literature; in practice, the conventional 'definitive' shape of the new device seems to have lasted but a short moment in time.

This history of the practices of the three companies examined highlights in particular the fundamental ambiguity on which the myth of the 'French' tableau de bord has been built. Are we talking about the tableau de bord used by operational managers or about the tableau de bord used by the board of directors? What representing/intervening tandem are we dealing with? The 'little history' of tableaux de bord refers to the model of the engineer based on the operational data/operational decision-making tandem. It portrays engineers as the source of tableaux de bord which they designed to convey operational information for decision-making of the same type. Yet, archival research produces more mitigated findings. The role of the engineer was perhaps less central than it first appears and the representing/intervening tandem in particular seems to rely on a blend of financial data and management by numbers. In this respect, the archives reveal the fundamental ambiguity of tableaux de bord: does the single, unified tableau de bord used at all levels of the corporate hierarchy really exist? And, as a corollary, this begs the question: is the tableau de bord specifically French?

The following paper sets out to show that the history of the French-style tableau de bord, broken down into four stages, is less linear than it first appears. From this history we draw out discussion points relating to the concept of the tableau de bord and point to new paths for interpreting the representing/intervening tandem. To this end the paper is structured as follows. Firstly, we describe our methodological approach and indicate the nature, and limitations, of the archival material to be used. We then discuss the concept of the tableau de bord around three critical issues: the role of engineers in its early design; its uniqueness as a device in the organization; and its French specificity. In conclusion, we will try to outline what is the purpose of tableaux de bord.

\section{Methodology and sources}

In order to confront the general idea of a tableau de bord and the reality of practices, our study is based on an examination of the archives of three large companies: Lafarge, Pechiney and Saint-Gobain. Since tableaux de bord have generally been seen to have been implemented in large industrial firms, the selection of these three companies will enable us to shed new light on the history and emergence of tableaux de bord in France. It will enable us to place in perspective the largely mythical view that has previously existed regarding the development of the tableau de bord. Lafarge, Pechiney (taken over by the Canadian firm Alcan in 2003), and Saint-Gobain are multinational industrial companies of French origin. Their particularity is that they have all been in existence for over one hundred years. Today, Lafarge operates mainly in the sectors of cement, plaster and aggregates; Pechiney, in the aluminium sector; and Saint-Gobain, in the sectors of glass, insulation and building materials. In the past, Pechiney and Saint-Gobain also operated in the chemicals sector.

Our choice of companies obviously provides a limitation to the study, as does the nature and scope of their archives. Indeed, the archival sources studied vary in size and are uneven in value. The Saint-Gobain archives were the most fertile in terms of both quantity and quality. The Lafarge archives were low in quantity but high in quality (e.g. Marcel Demonque's tableau de bord). The Pechiney archives have been studied previously and have generated many research works that have been useful for the purposes of this article. 
Nevertheless, the choice of companies to study is not without significance: one of the strongest assumptions underlying previous research cited above is that engineers played a central role in designing the first tableaux de bord. Each of three companies examined exhibited a strong technical culture over the study period and this will therefore allow us to test this assumption.

The methodological approach adopted here is based on the critical approach to history. This requires studying the archives (primary sources) within a four-dimension protocol: utilising cross-checking procedures, both internal (within the archives) and external (with secondary sources); choosing a chronological sequence and building a storyline; referring to local sources; and, layering the story obtained with quotations taken from the archives.

\section{A turbulent history}

Four stages mark the emergence of tableaux de bord in the three companies studied. The first, at the turn of the twentieth century, was characterised by the appearance of written reports, i.e. use of the narrative form to convey information from the periphery to the centre. The second stage, during the interwar period, was marked by the increasingly commonplace use of 'statistics' for sales, production, etc. This stage foreshadowed the emergence of tableaux de bord but, in the end, it was budgetary control that would be adopted. The third stage in the 1950s and 1960s marked the true emergence of tableaux de bord. However, in the final stage, we observe the tableau de bord's rapid slide towards a reporting device of a financial nature.

\section{Narrating the running of factories: written reports}

Lafarge set up conseils de fabrications, or 'manufacturing committees', from 1885 onwards. They brought together the company's senior management and operational managers/engineers. The purpose of the conseils de fabrications was to address essentially technical questions and to find solutions for a number of production problems that Lafarge was experiencing at that time. Each meeting was the subject of a report, hand-written in the early meetings and subsequently typed. These reports were then bound into volumes. From that point onwards, the information gathered took a narrative form; incidents, problems and solutions were related in the form of a story.

At Saint-Gobain, a reference to rapports hebdomadaires, or 'weekly reports', figures in a 1916 memorandum relating to a period beginning in 1880. In 1912, new recruits from the Inspection des finances, top-tier civil servants specialising in public finance, set up financial reports. Finally, in 1920, a memorandum from general management entitled journal de marche, or 'logbook', reiterated senior management's expectations (Saint-Gobain Archives, CSG Hist 00077/26, Memorandum of $6^{\text {th }}$ October 1920 from head office to factories):

We would remind you of our memorandum $38-\mathrm{F}$ of $29^{\text {th }}$ June 1916. Several plants possess books that are kept up-to-date and are likely to provide accurate and interesting data: this should be the case for all our sites. Please specify where your site is with regard to this issue and, if our prescriptions have not yet been followed, to move forward rapidly to make up for lost time. 
However informative they may have been, from the perspective of the theoretical definition these reports did not constitute tableaux de bord. The portion set aside for story telling remained significant and the data that appeared in them were not systematically organised.

Over time, the written reports would incorporate increasing amounts of data in the form of figures. After the First World War, boards proclaimed their need for 'statistics' relating to sales, production, and personnel. However, in the end, this demand for figures would lead to the adoption not of tableaux de bord but of budgetary control.

\section{Statistics, tableaux de bord or... budgets?}

The interwar period saw the development of schools of thought in management among French industrialists (Berland 1999; Kuisel 1984). A book published by Robert Satet in 1936 illustrates well the style of the literature that proliferated in this era. He argued in particular for the adoption of 'appropriate documentation', i.e. 'statistics of which a judicious selection is necessary to reach the goal that has been set out' (Satet 1936, 85). To give an example, Satet $(1936,85)$ presented the case of a textiles company:

In the company in question, three types of statistics are kept depending on whether they methodically bring together in the following domains facts that lend themselves to numerical assessment:

1. Commercial and economic statistics;

2. Industrial statistics;

3. Financial statistics.

Table 1 shows what kinds of statistics should be implemented in practice in each of these three categories. Satet attributed to each of them a goal, a frequency and, where appropriate, observations.

Table 1 - The statistics recommended by Satet (extract)

\begin{tabular}{|c|c|c|c|}
\hline Type & Goal & Frequency & Observations \\
\hline $\begin{array}{c}\text { Commercial Statistics } \\
\text { wool and combed wool }\end{array}$ & $\begin{array}{c}\text { Orientation for } \\
\text { purchasing raw } \\
\text { materials }\end{array}$ & $\begin{array}{c}\text { Monthly or } \\
\text { daily (combed } \\
\text { wool) }\end{array}$ & $\begin{array}{c}\text { It also serves in interpreting variances } \\
\text { between results and forecasts }\end{array}$ \\
\hline $\begin{array}{c}\text { Industrial Statistics } \\
\text { production rates }\end{array}$ & $\begin{array}{c}\text { Observation of } \\
\text { production rates in } \\
\text { order to regulate the } \\
\text { pace }\end{array}$ & Daily & Monthly \\
\hline $\begin{array}{c}\text { 7. Contractors' } \\
\text { production costs (on } \\
\text { average and per item) }\end{array}$ & $\begin{array}{c}\text { Comparison of the real } \\
\text { cost of production with } \\
\text { that of contractors }\end{array}$ & $\begin{array}{c}\text { In some cases it may be advantageous } \\
\text { to turn to contractors that are cheaper; } \\
\text { likewise in cases of seasonal backlogs } \\
\text { of orders to respect delivery deadlines }\end{array}$ \\
\hline $\begin{array}{c}\text { Financial Statistics } \\
\text { 13. Statement of price } \\
\text { reductions granted to } \\
\text { clients for second- } \\
\text { choice goods }\end{array}$ & $\begin{array}{c}\text { Wastage in sales which } \\
\text { must be accounted for } \\
\text { in the general } \\
\text { operational budget }\end{array}$ & Monthly & $\begin{array}{c}\text { Also serves to monitor defects in the } \\
\text { departments concerned }\end{array}$ \\
\hline
\end{tabular}


Source: Satet $(1936,87)$.

Although we can see the first outlines of a tableau de bord in this example, it still remains the case that Satet's book pertained to budgetary control $(1936,85)$ :

One can hardly conceive of budgetary forecasts being developed without the support of appropriate documentation, drawn from observations of phenomena proper to the company and from those of a more general nature that relate, for instance, to markets for materials purchased and manufactured by the company.

Satet therefore assumed strong complementarities between statistics and budgeting, making the former the prerequisite for the latter to exist. This complementarity between the two devices would certainly contribute to the ambiguity that was to characterise the history of the tableau de bord (see below).

Indeed, statistics did appear in our three companies during the interwar years. At Lafarge, figures had been incorporated into written reports from 1905 onwards and the table format came to be used. By the end of the 1920s, these data, dispersed until then, became more consistent, in particular information on technical and commercial matters (namely, customer complaints). At Pechiney (at that time, called Alais, Froges et Camargue or AFC), commercial statistics were kept from the 1920s onwards. Another domain given to statistics was personnel management.

The development of statistics was often in response to external demands from various sources: commercial expectations, professional bodies (such as the Union des industries métallurgiques et minières or the Union des industries chimiques), public authorities (notably during the war), and even national and international bodies (for instance, from the INSEE, the French Statistics and Economics Institute, or the OECD). Tabulating (statistics) machines ${ }^{1}$ contributed to the rise of statistics from the 1930s onwards. Cailluet (1995) points out that, at the end of the Second World War, eleven statistics machines were in common use at AFC. In addition to accounting, they handled sales statistics (AFC and Aluminium français) per region, per agent, per client, and per product (40 per cent of total machine activity), and provided various statistics on the personnel. A restructuring programme carried out by the White consultancy in 1947, which would mark the onset of budgetary control, revealed the true position of statistics in the company's management system. At that time, the head of the financial department shared his concerns with the managing director, Raoul de Vitry:

Neither of these reorganisers [...] seems to have very precise notions of accounting strictly speaking, of which bookkeeping is a mandatory feature and which they tend to confuse with simple statistical indicators that we may envisage deleting.'

(Memorandum of 24 January 1948, quoted in Cailluet $(1995,81)$ )

The author of the memorandum makes a clear distinction between accounting (financial in this case) and statistics. ${ }^{2}$ We later observe that this distinction has not always been respected.

Yet, it was at Saint-Gobain in particular that the slide from demanding 'statistics' a requirement clearly formulated by senior management and backed by consultant engineers - towards adopting budgetary control would be observed. The work of Lacoin, a consultant engineer, between 1934 and 1936, included among other things a study of the documentation needed by the Board. 'Statistics' were mentioned; Lacoin recommending 
the implementation of a 'method of documentation' for each sales agent to include the following information:

- Sales results - current and comparisons with those of previous years - for each and all of the main products $[\ldots]$;

- Remuneration and expenses of the agency included in the turnover and in the means of action: mileage, business trips, advertising, etc.;

- The main clients ranked by volume of sales and notably clients won or lost over recent years, with the reasons for their loss;

$[\ldots]$

- Delays or quality defects that gave rise to customer complaints, actions taken;

- Sales with critically weak profit margins and the local competitive environment;

- The share of St Gobain sales in relation to total sales in the agent's zone Potential sales in light of rival products [...]

(Memorandum of 19 June 1934, Saint-Gobain Archives, CSG 000420/18)

Lacoin also underscored the importance of commercial information for positioning the company in relation to competitors: 'how do Saint-Gobain's means of action behave in relation to those of its main competitors, with respect to both its geographical distribution and the tooling of its factories, and to its commercial organisation [...]?' (Executive committee report, 1934, Saint-Gobain Archives, CGS 000420/18). Finally, the report emphasised the need to 'choose several important issues by studying them in depth' (Memorandum of 22 October 1936, Saint-Gobain Archives, CGS 000420/18). The tone of this text makes us think unquestioningly of tableaux de bord since it stresses the relationships between various means of action and outcomes. Furthermore, it supplements financial data in a way that anticipates the systemic reasoning of the BSC. However, we should note that its subject matter was exclusively commercial.

More broadly, the context of the 1930s brought with it dissatisfaction with 'the absence of command' by the Board of Directors, with difficulties in getting information to flow upwards in light of the increasing dispersion of activities. A memorandum circulated on 13 September 1933 (Saint-Gobain Archives, CSG 000417/171) describes the 'tentaclelike developments [...] in the most diverse countries and in the widest variety of domains' of the company. The numerous memoranda of that period issued by either the consultant engineer Lacoin or by the company's general management reveal a growing need for information. A large number of requests conveyed by the general management to factories demanded that information be communicated: monthly deliveries per product/market, inquiries into wages and employees, accident reports, etc. (Chemical Products - General Management Memoranda - 1936-1938; Saint-Gobain Archives, CSG Hist 00077/26). Also mentioned were demands emanating from various government departments (the Mines and Factory Inspectorates) to which senior management sought to respond in a centralised way. Printed forms to be filled in were sent out, but there was still no question of a formalised tableau de bord. In 1936, the memorandum of 23 June from the Department of Control and Economic Analysis recommended 'the continuous observation of the subsidiaries' (quoted in Nikitin 1989, 23). On 15 February 1938, the Board requested that management teams gather from the subsidiaries, for the General Secretariat, 'the main indications of a technical and commercial nature, as well as the balance sheet and the financial results of the company' (Saint-Gobain Archives, CSG Hist 00077/26). It also referred to a quarterly frequency that was adopted in 1936. Finally, the 'reorganisation of the accounting departments' carried out by the former Financial Inspector Caillet led to an inventory being drawn up: 
But analysis, statistics, financial studies, the analysed results, in a word 'the accounting', was only mediocre... Its sole aim remained the maintenance of cash flow. It attended to the most urgent things first [...] RESULTS, ANALYSES, and STATISTICS concerned no one.

We want accounting to become once again the company's compass (...) a precious auxiliary. $^{3}$

(Saint-Gobain Archives, CSG Hist 00077/29, Memorandum of 30 November 1938)

These repeated requests corresponded, quite probably fortuitously ${ }^{4}$, with workshop practices. A series of reports can be found in the Saint-Gobain archives, dating from 1937 to 1953, issued by the Glaceries (the old term used for glass-making factories) and pertaining to shifts in production costs (monthly, per product, per type of expenditure, per manufacturing stage) as well as to technical information (production levels, yields, energy overheads, etc.). These reports were printed on large A3-sized pages and were completed with written analyses in the form of small reports.

In 1938, a memorandum circulated by the same sector of activity stated:

the usefulness of a comparison between the figures provided by the different factories is self-evident. This comparison is currently very imperfect because any single figure is not interpreted in exactly the same way by all the sites. The aim of the present memorandum is to specify the definitions of the items that appear in the technical reports and the production costs.

(Saint-Gobain Archives, CSG Hist 00006/06, Memorandum Halle à verre mince 'Instructions on drawing up technical reports and production costs' - 10 January

This memorandum recommended writing bi-weekly and monthly technical reports containing manufacturing data and including an executive summary (the 'salient facts'), information on manpower (employees, time worked, wages, etc.) as well as information on production costs. This memorandum also presented models of tables. It specified that 'the figures used in the bi-weekly report must be as accurate as possible without necessarily being accounting figures. Figures presented in the monthly report will be, in contrast, "accounting" figures'. Here, we should note the Board's goal of having at its fingertips information that went beyond accounting and financial accounting. ${ }^{5}$

The demand for information was therefore recurrent in a context perceived as complex due to geographical dispersion and diversification in the activities of a group in full mutation. However, the ambiguity inherent in this quest for information was strong. Thus, a memorandum from Lacoin, although emphasizing the need to 'choose several important issues by studying them in depth', drew up the following list:

'1.- An in-depth periodical examination of financial results, and, from there, the examination of the situations to which they pertain:

- Annual profits per product and margins compared with the working capital tied up in the main products.

- Factory results, production costs, margins, utilisation of capacity. These results will be compared with observations relating to scopes of action and potential factory closures.

- Sales results per region and per customer type - Shifts in the clientele and shifts in competition - The Board is not receiving precise information on 
this subject, whereas it is already possible to compile some interesting data and it would be very easy to complete this information. Shifts over several years in sales prices and production costs, and items that make up production costs. For fertilizers, comparisons with prices per region and per product from previous years, after each campaign and at the end of the year. $[\ldots]$

2.- Examination of the means of action with a view to improving them and mainly: $[\ldots .$.

[The list notably includes: payrolls, budgets, research programmes and new product launches, the organisation of departments, etc.]'

(Saint-Gobain Archives, CSG 000417/171, Memorandum 22 October 1936)

We can clearly see in this formulation the blurring of lines between data gathering of a budgetary nature and the basic elements for building a tableau de bord.

Yet, even though Lacoin specified that to these data 'should be added a control of the quality of work: customer complaints, delays in deliveries to customers, unpaid bills', what was proposed related more to budgetary control than to tableaux de bord, and it was indeed the former device that would be adopted rather than the tableau de bord.

The Héranger mission, named after another consultant engineer working for SaintGobain from 1941 to 1948, would result in the implementation of structures (general management organisation, the plan, and the position of financial deputy) and methods (budgeting and industrial accounting). ${ }^{6}$ At that time, all the initiatives seemed to lead to budgets and management accounting and, despite the claim for something less financial, the tableau de bord was slow to materialize.

However, the need for another instrument still made itself felt. Héranger therefore put in place a system of monthly reports and inventory reports (factories, sales, etc.). In a memorandum to the Chairman in March 1945, he noted that 'in a small business, the boss sees his colleagues and his workers every day [...] and to manage his business he can content himself with his personal perspicacity and a minimum number of documents' (Saint-Gobain Archives, CSG 01651/10, Memorandum from Charles Héranger to the CEO, March 1945). As the business develops and tasks are delegated, however, the memo went on, the boss needs 'a small number of periodical reports, in the light of which he makes his decisions'. Competition and economic instability, the memo stated, reinforces the need 'to assess more frequently the company's situation using reports with figures designed as true instruments of management and decision-making'. Here, we again find the major ambiguity of this period leading in the end to the implementation of budgetary management. Moving from direct and exhaustive information for the head of the company to information that is selected, intermediated and put into figures is not straightforward. Budgetary control, however, did not respond fully to needs; a series of memoranda dating from 1945 again referred to problems regarding information. In a memorandum of 9 August 1948, the Héranger mission stressed the need 'to study and perfect the accounting and statistical documents necessary for running senior management and the departments' (Saint-Gobain Archives, CSG 01651/10, Memorandum from Charles Héranger to the CEO).

In parallel, two other phenomena militated in favour of the adoption of the tableau de bord. The first was tied to requests from the State administration and from its various committees in the form of selective information or more in-depth enquiries. This was particularly true during the Second World War. The second phenomenon related to overseas trips made by the members of the Board and, in particular, to the discovery of the American model. Following a six-week trip in 1946 to Ford, Blue Ridge Glass, Corning, 
etc., Caillet contrasted 'our diverse manufactures, our geographical dispersion' to the centralisation of American companies: 'each company has the luxury of sales statistics', and 'very advanced studies'. He enthused about the 'speed in producing accounting and statistical documents', the excellence of the personnel and the use of mechanical data processing (Saint-Gobain Archives, CSG 01651/10, The Caillet Report 'Administrative and Accounting Organisation in the USA' - 31 January 1947)

\section{And finally, the tableaux de bord}

In the 1950s, we find examples of both directors' tableaux de bord in completed form and a theorisation of the device.

In the middle of the 1950s, the tableau de bord underwent its first formalisation. The CRC (Centre de recherches et d'études des chefs d'entreprise), at Jouy en Josas, near Paris, frequented by directors of large companies including Saint-Gobain, Lafarge and Pechiney, published a handout entitled 'Industrial Accounting - Tableau de bord' containing a section on the 'Techniques of the TABLEAU DE BORD in the service of corporate management'. It goes on to describe:

The term suggests a car driver, train driver or pilot... who has displayed before his eyes a number of dials providing indications that help him to drive or fly [...]

Each flight in a plane corresponds to a financial year in progress during which the role of the company boss is:

- To develop his means in terms of materials and men;

- To turn any unfortunate trends around rapidly, events that will not fail to occur due to the difficulties encountered en route.

To be a good pilot who flies well and reacts quickly, the company boss must be an 'aware' and 'informed' pilot, like the captain on a flight deck. Of course, if the weather is clear and the wind favourable, the pilot barely needs to look at his dashboard. But when the bad weather comes, he must be able to fly without sight.

(Saint-Gobain Archives, CSG Hist 00005/1)

The company boss's tableau de bord must therefore include: 'level gauges' (inventories, cash flow, customers, suppliers); 'totalisers' (expenditure, purchases, production levels, sales, per type, per workshop, etc.); 'ratio calculators' (production costs per unit, turnover/inventory-type ratios or indirect hours/total hours-type ratios); 'variance calculators' (comparisons between years, with forecasting, etc.; indices of a turnover N/turnover N-1 type; of a relative variance type [(real cost - forecast cost)/forecast cost]); and finally, 'indicators relating to the external environment', and notably 'items for professional or regional comparisons pertaining principally to product markets, and the labour market'. Furthermore, we find the importance of form (Saint-Gobain Archives, CSG Hist 00005/1):

In addition to these five categories of dials that provide him with data expressed in numbers written into tables, it will be useful to the company boss to express certain indications in the form of numbers drawn on diagrams. These diagrams will transcribe all or part of the numbers written on the tables. To be drawn on the diagrams will be numbers that express facts that need particular monitoring. 
This document from the CRC is interesting for another reason: it addresses the 'practical processes for implementing the dials of a tableau de bord'. The tableau de bord should possess five features to ensure 'rapid reactions':

- Displaying a limited number of indications: 'choosing between all the possible information';

- Developing secondary tableaux de bord: the tableau de bord must be 'split' between the agents;

- Choosing the frequency of calculation depending on the type of indication;

- Ensuring the instantaneousness of the indications and the speed of the information;

- Other practical considerations.

On this last point, several methods were mentioned: duplicating selected indications on wall charts, on rotating boards, in 'a small notebook that the company director carries with him at all times'; filing without duplicating reports provided by the departments. Practical aspects were particularly elaborated:

A practical filing process [...] consists in using sheets superimposed and ordered in such a way that only one column, or one row, is ever visible. This process also allows the main tableau de bord and the secondary tableaux de bord to be input simultaneously. Filing these sheets in a ring binder enables the company boss to have at his disposal a discrete tableau de bord (a wall chart is not discrete) that can be easily transported from the office and used in places away from the telephone to allow purposeful thinking.

[...] It is essential that diagrams be placed next to the families of numbers from which they result to facilitate viewing.

For moving from one year to the next, transparent diagrams, on frosted cellulose film (KODATRACE), can provide good service.

The document finishes with an Appendix containing the tableau de bord of a foundry with numerous diagrams, but it clearly warns, 'It is an example and not a model. Each managing director must have a tableau de bord adapted to his temperament. This is the first condition for its effectiveness'. In contrast, the bibliography illustrates the novelty of the instrument since it was taken from a book on Ratios published by the Société Expertise comptable fiduciaire de France [1961].

In 1959, the Cegos Institute published a 'Report of an enquiry into the orientation of works in Section 3 (general management)'. It presented the results of a questionnaire of seventy-two managing directors relating to priority subjects for the programme of study and exchange of Section 3. The subject of the tableau de bord is in third place in the chapter 'The boss's personal organisation', behind the topics of information and of the managing directors' documentation. Taking all the categories as a whole, it was the tableau de bord that was most frequently cited.

It was also in 1959 that the first edition of a work by Lauzel and Cibert appeared, Des ratios au tableau de bord. ${ }^{7}$ This work, containing a fourth section dedicated to the tableau de bord, nonetheless remained heavily influenced by the ratio-based approach of a financial type. Only the sixth section, based on the case study of the Papeteries Schwindenhammer, presents a tableau de bord, undoubtedly anchored in budgeting, but composed of indicators of all types.

With regard to companies, the tableaux de bord also began to appear during this period. At Saint-Gobain, the first genuine tableau de bord belonged to M. Grandgeorge, 
the managing director. This 'tableau de bord of the Glaceries' spanned the period 19521958. It contained three files, each entitled 'tableau de bord':

- Tableau de bord no. 1: commercial management

- Tableau de bord no. 2: technical management and financial management

- Tableau de bord no. 3: wages, social contributions and purchasing power.

(Saint-Gobain Archives, CSG 01650/224)

In reality, it consisted of a collection of slightly disparate documents corresponding to different periods. Certain annual indicators went back as far as 1912, in all likelihood on the basis of reconstituted data; others were monthly (1954-1955) or half-yearly, etc. Two notable features are worth highlighting, however: the first is that these tableaux de bord contained numerous coloured tables and diagrams; secondly, the data were essentially nonfinancial - the financial section of Tableau de bord no. 2 does not appear in the file. ${ }^{8}$

In 1955, a memorandum from general management (chemical products) addressed to Grandgeorge (Saint-Gobain Archives, CSG Hist 00074/14, Memorandum 'Tableau de bord of chemical products' - 2 September 1955) was intended to be a 'first attempt to gather together tables and diagrams relating to the activities in chemical products as seen from the standpoint of the company's general management'. Once again, it consisted of a collection of existing documents, either annual (production, sales) or monthly (here, it refers to a note book containing data on invoicing, inventories, deliveries, and results). The author of the memorandum is fairly critical: he remarks on badly designed diagrams that are barely readable, but 'the main hole that still needs to be filled is the total absence of items for forecasting'. More broadly (Saint-Gobain Archives, CSG Hist 00074/14):

To conclude on this first trial, in order to succeed in gathering really useful and easily readable documents - without imposing an excessive material workload on the different managements responsible - it would seem desirable to lay out for them a doctrine and a uniform and fairly rigid framework for presenting statistics.

According to our information, such a method is in force at SHELL which is applying it in each of its operational plants throughout the world.

At Pechiney, the tableau de bord was first mentioned around the same time. In 1954, Jean Benoit, returning from the tenth International Congress on Scientific Management, noted in a report (Pechiney archives, 00-10-10021, Memorandum of February 1954) that, 'the method of managing by exception appears indispensable to the managing director'. Yet, in addition to 'standard cost accounting' and budgetary control, he mentioned 'qualitative methods of a self-reporting type that are beginning to emerge' and 'the interest of selective rather than complete reports'. To be considered as 'a particularly powerful means of assessment' are the 'systematic analysis of customer claims $[\ldots]$ the reasons for their leaving and complaints from the company's agents'. A link may be drawn here between commercial statistics and statistics relating to personnel (see above).

In 1955, Raoul de Vitry, Deputy Chairman and Managing Director of Pechiney, addressed a conference on the subject of 'the tableau de bord of a captain of industry'. ${ }^{9} \mathrm{He}$ specified:

These terms, perhaps a little evocative, represent the set of measures that the company's Board of Directors, supported by accounting, is driven to adopt today to ensure the best possible conditions for: its information, the making of its decisions, 
and the monitoring of their execution. [...] By 'accounting', we mean all the periodical documents with figures: accounting statements, balance sheets, production costs, statistics, budgets, ratios, etc.'

(Pechiney Archives, 001-7-130994)

After drawing up an American-style 'background' from the pre-1914 'treasurer' to the 'controller', Raoul de Vitry noted that the trend was moving towards more interpretation, assessment, and analysis. He praised budgetary control highly, but highlighted its complementarity with the tableau de bord ${ }^{10}$ :

Which, under these conditions, appears rather more like a kind of radar and includes the following main elements that I will succinctly reiterate:

1. The choice of the key metrics of which we seek to follow the variations: production and turnover, results, investments, statistics, cash flow, employees, wages, no more than a few ratios with the denominator of gross operating margin or approved items from a year of reference appropriately chosen;

2. Monthly and cumulated forecasts corresponding to the previous key metrics; 3. Comparison through a convenient material process of real performance and forecasts;

4. Rapid communication to all levels of the hierarchy of the previous documents for the parts that concern them as well as interpretation of any variances, should they arise.

(Pechiney Archives, 001-7-130994)

Raoul de Vitry saw in the tableau de bord the ideal instrument for the 'method by exception':

the ideal would be that managers at all levels no longer have to take care of their tableau de bord - no longer set the values that condition the calibration of weighing devices - but that they are sure that there exists in the company, carefully hidden under the bonnet, a mechanism that is accurate, sensitive and error-free, that does not flash numerous lights in their eyes to signal minor anomalies but instead, selects them for each level of the hierarchy, in such a way that each manager need only take into account anomalies that are relatively uncommon and worthy of attention, and which require his attention.

(Pechiney Archives, 001-7-130994)

The director's tableau de bord thus enables him to save time for long-term reflection. More broadly, Raoul de Vitry advocated standardisation within the aluminium sector: 'Otherwise, how can we conceive that too great a dispersion of companies and the means of production may resist internal rivalry and powerful and dynamic external competition?' (Pechiney Archives, 001-7-130994). Finally, in the conclusion to his report, Raoul de Vitry suggested that (Pechiney Archives, 001-7-130994):

The 'machine for governing companies', a kind of ultimate term for the development of a super tableau de bord, may seem to come from the world of dreams and in a time span that I dare not specify, but it does not seem beyond reason. 
In addition to these essentially theoretical developments, the tableau de bord underwent practical applications at Pechiney. The restructuring carried out by the White Consultancy in 1947 conferred a new responsibility on the Department of Industrial Organisation - building tableaux de bord. Cailluet (1995) points out that the Group's Chairman and Managing Director, Pierre Jouven, had at his disposal a tableau de bord at the beginning of the 1950s. It contained eight chapters (Cailluet 1995, 87-88):

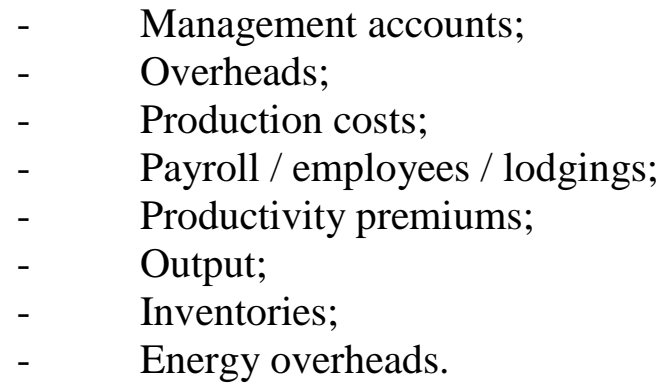

The chapter on production did include a series of technical indicators, but Cailluet (1995) observes strong parallels between the tableau de bord and budgetary control.

At Lafarge, the tableau de bord belonging to Marcel Demonque, Chairman and Managing Director from 1959 to 1974, was presented in the form of a file. Five filedividers split it into separate sections: deliveries, results, investments, the situation, and personnel. The information was very diverse and included both financial and non-financial data. It was composed of numerous tables and hand-painted diagrams which were directly readable. We choose two illustrations as examples: first, a diagram comparing the delivery to customers, factory by factory (see Figure 1); and second, a diagram showing details about personnel unionisation per factory and category (see Figure 2). These illustrations highlight the diversity of data collected and the importance of its "staging" in a simple, readable form.

\section{[Insert Figures 1 and 2 about here]}

Nevertheless, it seems that Lafarge was behind in realising this tool's potential. In 1968, Marcel Demonque remarked that, 'it has become indispensable to define methods for managing our businesses [...] with the large number of our entities, geographical spread and the diversity of our business sectors' (cited in Public Histoire 1991, 45). The Group began an overhaul that was carried out by the consultancy firm McKinsey between 1965 and 1969. The new organisation aimed to be decentralised and to rely on rolling planning, budgetary control and management by objectives.

In 1973, during a seminar chaired by the Deputy Chairman, Olivier Lecerf, criticism of the budget, viewed as too cumbersome, opened the way to 'less sophisticated methods' aimed at creating 'a genuine central industrial power' to face the autonomy of the branches (Lafarge Archives, B 2-1). However, nothing specific was proposed. In 1974, a memorandum entitled 'Department of planning and budgeting' planned to reform the 'logbook'. The memorandum's author specified, 'I have set myself the absolute priority of ensuring that tableaux de bord are produced in the state in which general management wishes to have them' with 'considerably shortened time lapses for providing information' (Lafarge Archives, B 2-2). The logbook had, however, a rather financial look about it since it contained mostly profit margins. A similar trend can also be found at Saint-Gobain. 


\section{From the tableau de bord to reporting?}

At Saint-Gobain, a study in 1959 by Paul Francin, General Manager of the Financial Department, suggested the adoption of four documents:

1) A tableau de bord for the financial department;

2) Financial metrics from the divisions' tableaux de bord;

3) Ratios to be used to assess an entity's situation;

4) An appendix: four summary tables.

(Saint-Gobain Archives, CSG 01650/224, Memorandum on Setting up the Tableau de bord - Study of Ratios - 5 February 1959)

This was a specifically financial instrument that nonetheless presented some of the features of a tableau de bord with, in particular, objectives, definitions, norms (for instance, a ratio should be $>1$, according to activity type) and clearly defined frequencies for the various indicators (monthly, quarterly, annually). Its format (financial tables - profit and loss - but also ratios and diagrams), the long-term goals set (future prospects - for cash flow), and comparisons (real/forecast, real n/real n-1, Saint-Gobain/other companies operating in the same industry) also gave this instrument the look and feel of a tableau de bord. A reminder of the need for more than financial accounting data using ratios (the gross operating margin in particular, per product family with a turnover greater than 10 per cent, for instance) and the selective nature of the information presented also contributed to this impression.

It was designed to complement budgeting and cost calculations:

Given the use of the budgetary control method, it will be suitable for divisions to provide in their monthly tableaux de bord a brief overview of the scale and the cause of the observed budgetary variances [...] Furthermore, given that the budgeting method used for production costs will be a fixed budget, divisions should indicate $[\ldots]$ an order of the scale of variance in the future:

1) of the gross operating margin;

2) of percentages of general expenses.

(Saint-Gobain Archives, CSG 01650/224, Memorandum on Setting up the Tableau de bord - Study of Ratios - 5 February 1959)

This undeniably makes it a financial instrument.

In the 1960s, budgeting began to disappoint as it became 'viewed more as a system for recording than as an instrument for managing'. A research project into budgetary management was conducted in 1963 by the Institut du contrôle de gestion (ICG) in several of the company's entities (Saint-Gobain Archives, SGV Hist 00020/04, Organisation of the Forecasting and Control Function in the Company - Investigation at the Company SaintGobain - November 1964). The section entitled 'Presenting Summarised Information: the tableau de bord', provided a definition:

The tableau de bord is a summary document that brings together in a coordinated and concise manner the important outputs of the factories, divisions and the company as a whole - sales, expenditure and results - with the goal of enabling us to refer to the past, to find statistical data items and to steer the board's decisionmaking in line with shared objectives: in it, one will find the construction of data items, their shifts and trends, then a succession of sound information for setting future budgets and for medium-term studies. 
This definition is disappointing if compared to the theoretical definition given earlier in this paper. However, the tableau de bord relating to hollow glassware production that appears in the report is indeed a tableau de bord; that is it contains a variety of data, especially a large number of non-financial data items. Its customised nature is recognised: 'there exist several types of tableaux de bord developed according to the personality of each director' (Saint-Gobain Archives, SGV Hist 00020/04, ICG memorandum).

Yet, by the end of the 1960s, the monthly tableau de bord for the glazing branch of the firm contained exclusively financial sections: sales, gross operating margins (with monthly variances in relation to budget targets), results of industrial operations as well as a commentary. A process whereby this tool became routinely used emerged from the restructuring of 1969. The administrative director, alongside other missions, 'operates the tableau de bord for the general management of the glass-making factories and proposes the summary formats that are most appropriate in this regard' (Saint-Gobain Archives, CSG Hist 00008/020, Job description). The management controller is responsible for 'determining, in agreement with the responsible directors, the nature of the information, both internal and external, that is worth putting into the tableaux de bord for the various levels of the hierarchy', and also for 'running the tableaux de bord of the general management and of the general director of the glass-making industries' (Saint-Gobain Archives, CSG Hist 00008/020, Job description). The administrative and financial management team was subsequently responsible for the tableau de bord and reporting became the norm. ${ }^{11}$

The history of tableaux de bord at Lafarge, Pechiney, and Saint-Gobain thus enables us to question assumptions underlying most research on this subject until today and, more fundamentally, to ask the question of what, in practice, is a tableau de bord. Indeed, the definition given earlier of a system of indicators that aim at monitoring and conducting economic operations and individual behaviours in a way that is compatible with the business strategy, does not exhaust the issue of what a tableau de bord really is and means. It has helped us to find, methodologically, historical traces of the emergence of the device. But, it does not address, other than in a descriptive manner, the question of what is a tableau de bord and what it means in practice for the different individuals and groups that implemented it. The next section examines this question.

\section{Discussion surrounding the concept of the tableau de bord}

The history outlined above, although rather cursory, raises a number of questions relating to the 'official' history of tableaux de bord. Two of these questions will be discussed here: firstly, the question relating to the origins (engineers?) and the scope (a single and unified tableau de bord?); and secondly, the specifically French nature of the device. These questions lead on to another: in the end, what is the purpose of the tableau de bord?

\section{Engineers at the birth of a single, unified tableau de bord?}

The history portrayed by the research cited in the introduction to this paper is based on two strong, if not explicit, assumptions - the assumption of the central role played by engineers and the assumption of a single, unified tableau de bord used by all, right through from the workshops to general management. ${ }^{12}$ Yet, one of the salient features of the empirical 
research presented above is the unobtrusiveness, not to say absence, of engineers. In this history we find directors, sales representatives, accountants, State bodies, professional bodies, etc. Yet, engineers, in their operational role, are curiously absent. Admittedly, directors may be trained engineers - and indeed, it is often the case - but here, they are acting as directors and not as operational managers or technicians.

In the genealogy of the tableau de bord, the reports studied at Lafarge and SaintGobain that were written at the end of the nineteenth century (see above) came from the factories. These reports addressed technical issues by and large and were in all likelihood drawn up by engineers. At Saint-Gobain, however, it was the arrival of Inspecteurs des finances that was followed by a need for financial reports. From its origins, therefore, an ambiguity existed between operational information spontaneously developed in the workshops and financial information requested by the hierarchy. Lauzel and Cibert (1962, 133) raised this very issue: 'We should not be thinking of a single tableau de bord, but of as many tableaux de bord as there are distinct and complex responsibilities within the company'. However, the remainder of the text subsequently focused on information 'in the sense of moving top-down as well as bottom-up through the hierarchy' (Lauzel and Cibert 1962, 134). They still appear to have a single, unified tableau de bord in mind, from which the information to be disclosed at each level is selected.

In contrast, Satet's recommendation to use statistics was balanced, advocating the use of commercial, industrial and financial statistics. It also foreshadowed relatively well, aside for the learning and growth perspective, what would later become the BSC. Indeed, business process, customer and financial perspectives were present. At Lafarge, the first statistics to appear in manufacturing reports were both technical and commercial. At Pechiney, they were commercial, accounting and personnel-related. At Saint-Gobain, commercial statistics also took a central position. And although they related mostly to technical details, in the important 1936 memorandum on 'Continuous observation of the subsidiaries', these data were framed by commercial and financial statistics. We do observe at Saint-Gobain the existence of reports containing figures issued by the factories (the Glaceries), but it is likely that this spontaneous information was first and foremost designed for local purposes. When the Board discovered the existence of this information, it was obviously tempted to request that it be sent upwards. But its own requirements went far beyond the technical information used for running the workshops and it was for this reason that Saint-Gobain implemented budgetary control.

Finally, the role of engineers in the emergence of tableaux de bord is real if we consider the local tableaux de bord used in the factories and the workshops. Directors themselves sought to implement a 'balanced' tableau de bord but struggled to find the appropriate form. This appeared to have been achieved in the 1950s when the Boards of Lafarge, Pechiney, and Saint-Gobain did have a tableau de bord at their disposal that was worthy of the name 'French' tableau de bord given to it in the literature. These were 'balanced' tableaux de bord in which technical indicators rubbed shoulders with commercial, personnel-related and financial indicators. What characterised them was that they best suited directors who knew their companies' activities intimately. For, as Hacking $(1983,245)$ states:

To be sure, he [the non specialist] would be unable to make the difference between a speck of dust and the salivary gland of the fruit fly until he has undertaken to dissect a fruit fly under a low magnifying microscope. This is the first lesson: to learn to see through a microscope, it is not enough to watch; you must do it. 
Beyond the role of the engineer, what is notable in this history is the role of directors who acted as if they were 'dissecting' activity. Regardless of whether they rose from the technical, commercial or other ranks, they were practitioners. Though it may be true that these directors were trained engineers, it was more their in-depth knowledge of the company's activity which was at the origins of the emergence of tableaux de bord, and this knowledge was not solely technical.

Furthermore, other sectors were involved: the State and its agencies; professional bodies such as trade associations through the demands they made on industrialists; competitors in the sense of their expectations; and even foreign companies through the examples they provided. The role of engineers consequently appears to have been somewhat diluted.

However, this observation needs to be put into perspective since information used in production workshops did exist. This phenomenon is barely visible in the archives and this constitutes a genuine methodological bias. Documentary archives tend to strongly favour sources that originate from the general management. Yet, even though our observation of the engineers' discretion should possibly be downplayed, it still remains the case that they do not appear to have been the main actors behind the emergence of tableaux de bord in France.

This first finding leads on to a second: the diversity of actors involved in the process of the emergence of tableaux de bord and, in particular, the central role of general management, also calls into question the single and unified nature of tableaux de bord. Indeed, it is clear that workshop tableaux de bord did not merge with directors' tableaux de bord, which, furthermore, were acquiring a distinctly financial look by the end of the period studied. The questions that emerge at this stage and that have significant ramifications on contemporary issues are fundamental in nature: what is a tableau de bord? Is it a totalising device that enables different levels of the hierarchy, by means of a system of consolidated indicators, to see what they can no longer see because of the factors of multiplication and distance? Or is it a local steering tool? Or are these two purposes compatible? To answer these questions, other empirical studies, and not only historical research, will be required. ${ }^{13}$ At this stage, however, historical research suggests that the single and unified nature of the tableau de bord is not self-evident.

Having nuanced these first two assumptions (namely, the role of the engineer and the single and unified nature of the tableau de bord), we can now turn to the question of the specifically French nature of the tableau de bord.

\section{A French specificity?}

This is an important question. Several facts tend to contradict the thesis of a specifically French tableau de bord as opposed to a totally finance-based Anglo-Saxon approach to management.

Doubt was first aroused by explicit references to foreign sources in the archives studied. Although it is true that, in the work of Satet, the presence of 'statistics' only relates to the French example presented by the author and not to the American example presented as a contrast, it still remains the case that Caillet at Saint-Gobain noted the existence of the 'luxury of sales statistics' on returning from a trip to the United States in 1946. He visited, among others, the companies of Ford, Blue Ridge Glass, and Corning. Also at Saint-Gobain, Grandgeorge, seeking to unify the system of tableaux de bord in 1955, referred to 'a method in force at SHELL that it applies to each of its operations throughout the world' (Saint-Gobain Archives, CSG Hist 00074/14 Memorandum from the 
chemical division). At Pechiney, Benoit seemed to discover 'qualitative methods of a selfreporting type' during the tenth International Congress on Scientific Management (Pechiney Archives, 00-10-10021). Furthermore, the shift in tableaux de bord towards a more classic system of financial reporting by the end of this period would mean that the specificity of the French model is weakened.

From the American standpoint ${ }^{14}$, Yates (1989) has shown that American management practices display strong similarities with French cases. She reveals the 'upward reporting' that is part of the techniques of 'systematic management' that appeared in the United States in the nineteenth century. A similar chronological sequence can be seen in the two countries. The technique of report writing appears in the nineteenth century:

When sales agents located in different cities supplemented their quarterly financial accounts with frequent letters about events and competition, they were reporting. (...) And in the few companies in which ownership and management were separated, managers reported to owners or their representatives. In general, these reports were not particularly distinctive in form: they were simply extended (but not necessarily well-organized) letters, sometimes accompanied by financial accounts in traditional double-column form. In the late nineteenth and early twentieth centuries, the form of business reports evolved significantly to fulfil the greater demands placed on them as firms grew and as the philosophy of systematic management gained in popularity.

(Yates 1989, 77-78)

The example of the American railroads is enlightening: in the 1830s and 1840s, reports were mostly financial, but operational data did still appear (on the number of miles of railroad, for instance). There was an emphasis on increasingly formalising and standardising the reports in the form of tables in particular. Their most appreciated features were readability and the ability to compare activity from one month to the next. Use of the telegraph made things easier: 'The telegraph and the tabular forms worked together to speed the flow of data without imposing excessive time burdens on senders or recipients' (Yates 1989, 78-79).

Yates observes the strong development of reports in all American companies at that time. They took different forms. Tables, whether hand-written or typed (following technical improvements in type-writers facilitating typing at the turn of the century), enabled reporters to move from description to comparison (tables with columns). The use of forms or sheets facilitated the work of 'inputting data': one just simply had to fill in the blanks. In the examples of tables and forms provided by Yates, numerous non-financial operational data can be found: 'Tables and forms made it feasible and reasonably efficient to collect, analyze, and transmit up the hierarchy the vast amounts of data needed for systematic control' (Yates 1989, 85).

The practice was theorised, in a very concrete way however, in specialist works:

The matter contained on the form should be arranged with reference to its sequence; the sequence of entry or computation and the sequence of matter to be transcribed from another form. On any sheet the spaces should be such that the entries are made first in the extreme left side spaces progressing across the right in order that the hand will not cover information already written down. Information to be summarized or transcribed should be placed on the right side so that the sheets may be handled with the left hand.

(Quoted in Yates 1989, 81-83) 
Diagrams made their appearance at the beginning of the twentieth century in response to the surfeit of tables and data at boardroom level. In his work of 1909, Carl Parsons presented diagrams as modern methods of management for anyone seeking to assess his activity at a glance. Other works on diagrammatical techniques for companies were published (Willard C. Brinton in 1914, for instance). Engineers, in particular members of the American Society of Mechanical Engineers, such as Towne, and obviously Gantt, promoted the graphical form from the 1880s onwards:

In many cases, the graphic method requires less space than is required for words [...] The great advantage is that with graphic methods facts are presented so that the reader may make deductions of his own, while when words are used the reader must usually accept the ready-made conclusions handed to him.

(Willard C. Brinton, quoted in Yates 1989, 85)

In the light of this American history, it is worth noting that the first edition of Satet and Voraz's work entitled Les graphiques, moyen de direction des entreprises only appeared in $1932 .{ }^{15}$ The work was fairly technical, but provided numerous examples drawn from company case studies and seems to have been the first in which the parallel with an airplane's dashboard appeared, though Satet and Voraz did not adopt the expression "tableau du bord", preferring 'boardroom charts'. Finally, the work referred to professional journals (Mon Bureau, in particular) and to the plentiful German-language literature.

In addition to the fact that the specifically French nature of tableaux de bord is called into question by these various elements taken from French and American history, one remaining issue emerges: given the empirical import of this investigation, it would seem useful to take another look at what the tableau de bord represents in companies.

\section{Conclusions: What is the purpose of tableaux de bord ${ }^{16}$}

The history of the tableau de bord, although rather cursory here, brings to light two major findings. The first pertains to the tableau de bord's 'why' or, in other words, what is their purpose beyond the suitable answers along the lines of rationality/efficiency/control? Using the works of Hacking, we show that the tableau de bord is a mode of representing which covers a number of choices. The second finding relates to the tableau de bord's 'how': in what way does the form of the device help managers? To borrow the expression used by Goody (1979, 58-60), tableaux de bord rely on the use of 'technologies of the intellect' that are capable of developing certain skills in those who use them. Tableaux de bord, by means of 'cognitive artefacts' (Norman 1993), enable us not only to see what cannot be seen by the naked eye, but also confers on managers new competencies with which they intervene in management situations. There is indeed both representing and intervening at play here.

Tableaux de bord, and their proto-historical form, the written report, emerged when the boards of companies lost direct contact with their businesses. Size and geographical dispersion automatically distanced directors from sales representatives, producers, personnel, etc. If they wished to remain informed, they had to invent a device enabling them, if it was not to see the state of their business, at least to represent it for themselves. Any mode of representation, however, requires making choices. The type of tableau de bord (balanced, financial, commercial, technical, personnel-related, etc.), the way of processing the data presented (transformation into figures, into monetary units, modes of calculation, etc.) and the scale of magnification (level of detail, frequency, level of 
consolidation, etc.) must all be chosen. These choices are of a kind that will alter the situations observed. It is at this point that we move from representing to intervening.

Goody (1979, 1986) and Norman (1993) have shown how 'technologies of the intellect' or 'cognitive artefacts' such as lists, tables or diagrams modify the skills of those who use them. According to Goody (1979), the written form produces three major consequences. The first is that putting into writing allows interpretation and manipulation. However, the $\operatorname{text}^{17}$ is also a reference because, 'literacy encouraged, at the very same time, criticism and commentary on the one hand and the orthodoxy of the book on the other' (Goody 1979, 37). The text therefore opens up opportunities to translate its meaning, even to betray its meaning, but also appears as the indispensable reference. The second consequence is that writing and in particular the modes of communication used (texts, but also tables, lists and forms) produce effects on individuals' cognitive capacities. Goody $(1979,36)$ thus analyses the 'role of changes in the mode of communication in the development of cognitive structures and processes, and in developments in the growth of human knowledge and in the growth of man's capacities to store and augment that knowledge'. The cognitive artefacts act as amplifiers of aptitudes and competences for those who employ them. Finally, the third consequence of the choice of the textual form is that 'the growth of bureaucracy clearly depends to a considerable degree upon the ability to control "secondary group" relationships by means of written communications' (Goody 1979, 15) as already shown by Max Weber. In other words, above and beyond the individual aptitudes that they produce, written forms of communication, the 'technologies of the intellect' (Goody 1979, 244), support modes of organising powers and the modes of control that are associated.

Tableaux de bord consist of cognitive artefacts. As a result, they allow a certain amount of manipulation, they dictate new behaviours/competences in users, and they are also auxiliaries of power. First of all, graphical and tabular forms do indeed open up both the possibility of building them in such a way as to highlight certain phenomena rather than others, and the possibility of interpreting them in potentially different ways. Secondly, tableaux de bord modify the competences of users. Yates (1989) notes in works dedicated to tables and diagrams at the beginning of the twentieth century the propensity of the authors to identify the skills developed by these cognitive artefacts: speed-reading, overviewing (at a glance), comparison, interpretation, projection, forecasting, persuasion, manipulation, and so on. And finally, tableaux de bord strengthen the power of the board of directors who see, without physically being there, what operational managers are doing in the field.

\section{Acknowledgements}

The research on which this paper is based has been carried out within the framework of a project financed by the Agence Nationale de la Recherche (ANR) entitled 'Management: Private Practices, Public Issues'. For their help in allowing me to access to the archives, I wish to thank M. Boutiron and $\mathrm{M}^{\mathrm{me}}$ Malherbe (Lafarge), $\mathrm{M}^{\text {elle }}$ Carbonell and M. Grinberg (Institut pour l'histoire de l'aluminium), and M. Hamon, Mahoudeau and M. Robinet (Saint-Gobain).

\section{Notes}


1 The 'machines à statistiques' (tabulating machines) were the antecedent of computing machines. They were invented by Hermann Hollerith at the end of the nineteenth century.

2 From a theoretical point of view, Gino Zappa was arguing from the 1920s onwards that cost accounting (which he referred to as 'statistics') should be kept separate from financial accounting. Indeed, he thought that financial accounting was incapable of capturing the reality of processes within the organization, anticipating the later work of Kaplan and Norton (Zan, 1994).

3. The distinction between accounting and other methods is not clear here. Accounting was perceived as an innovative method in contrast to merely managing cash flow. We may assume that, here, we are dealing with industrial accounting.

4. Indeed, it seems highly unlikely that data conveyed by the Glaceries met the requirements of general management. It seems that such data predated these requests.

5. Here, the distinction with financial accounting is clear.

6. For a history of budgetary control, see Berland (1999).

7. We have only been able at this point to consult the second edition dated 1962.

8 It is unclear whether this is because they were never generated or that they simply have not survived.

9. Unfortunately, we do not know which kind of audience he addressed.

10. The ambiguities between tableaux de bord and budgetary control are, however, far from being clarified in this report.

11. This is how the system still used in Saint-Gobain today, the SIF (Système d'informations financières), emerged.

12. Furthermore, it was this model that has been widely theorised (see, for instance, the OVAR method - 'Objectifs, Variables d'Action, Responsables' - developed by a French research group).

13. The examples of current tableaux de bord that are available to us, through the works of Masters students in particular, show that they are mainly financial reporting tools. Implementation of methods described as 'ways' (the Areva way, the Danone way, the Lafarge way, etc.) perhaps illustrates what a 'genuine' French-style tableau de bord would be. The company's social responsibility would appear to be the source of these initiatives (see the work of Moquet, thesis in progress at the University of Paris Dauphine).

14. Trevor Boyns has also collected some data about the case of UK industry: "Forecasting demand: a mean to more effective management" (presentation to the Association of Business Historians Conference, University of Reading, June 2002).

15. As of writing, we have only consulted the sixth edition dating from 1946.

16. In this section, it is directors' tableaux de bord that we have chosen as our focus.

17. Here, we use the term 'text' in its broadest sense to include 'technologies of the intellect' such as lists, tables, diagrams, forms, etc.

\section{References}

Primary sources

Lafarge - Archive collections available at the head office in Paris

B1-1 to B1-4: Management and manufacturing board meetings

B2-1 to B2-4: Management committees 
B3-1 to B3-5: M. Demonque's correspondence

C1-8.1: Economics / Profitability

C1-9: HR / Management

C1-13.1 to C1-13.3: Statistics

C3-4 to C3-5: Strategy / Planning

R4-10: Lafarge Canada (McKinsey Consultants)

Pechiney - Archive collections available at the IHA (Institut pour l'histoire de l'Amuminium), Gennevilliers.

001-7-30994: General Management

00-10-10021: General Management

Saint-Gobain - Archive collections available at the Centre d'Archives at Blois

CSG Hist 00074/1: General management of glass-making factories / tableau de bord

CSG Hist 00074/14: General management of chemical products / tableau de bord

CSG Hist 00005/1: CRC / Industrial accounting

CSG Hist 00077/009 to 025: Central administration / Department of control and economic studies $(1872-1941)$

CSG Hist 00077/026 to 028: General management of chemical products / Memoranda

CSG Hist 00077/029: Restructuring of accounting departments

CSG Hist 00004/283 to 4: IOIC

CSG Hist 00004/727: The Cegos Institute

CSG Hist 00008/020: 1969 restructuring

CSG 000417/57 and following: Board and committee meetings

CSG 000420/171: The Saint-Gobain organisation (1932-1958)

CSG 01650/224: Financial department / tableau de bord

CSG 01651/10: Héranger Consultants

SGV Hist 00001/00055, 00067, 00317: General management of glass-making factories

SGV Hist 00020/04 to 05: Budgetary control, BAG

Secondary sources

Ambly, P. 2000. Naissance d'une entreprise. Les Pavin de Lafarge. Paris: Ed. F.X. de Guibert.

Berland, N. 1999. L'histoire du contrôle budgétaire en France. Les fonctions du contrôle budgétaire, influences de l'idéologie, de l'environnement et du management stratégique. Unpublished $\mathrm{PhD}$ thesis, University of Paris Dauphine.

Bessire, D. and C.R. Baker. 2005. The French Tableau de bord and the American balanced scorecard: a critical analysis. Critical Perspectives on Accounting 16: 645-664.

Bourguignon, A., V. Malleret and H. Nørreklit. 2004. The American balanced scorecard versus the French tableau de bord: the ideological dimension. Management Accounting Research 15: 107-134.

Cailluet, L. 1995. Stratégies, structures d'organisation et pratiques de gestion de Pechiney des années 1880 à 1971. Unpublished $\mathrm{PhD}$ thesis, University of Lyon II.

Daviet, (J.P.) 1988. Un destin international - La Compagnie de Saint-Gobain de 1830 à 1939. Paris: Ed. des archives contemporaines.

Epstein, M. and J.F. Manzoni. 1998. Implementing corporate strategy: from tableaux de bord to Balanced Scorecards. European Management Journal 16, no. 2: 190-203. 
Goody, J. 1977. The domestication of the savage mind. Cambridge: Cambridge University Press. Translation used in the original paper: La raison graphique. La domestication de la pensée sauvage. Paris: Les Editions de Minuit, 1979.

Goody, J. 1986. The logic of writing and the organization of society. Cambridge: Cambridge University Press. Translation used in the original paper: La logique de l'écriture. Aux origines des sociétés humaines. Paris:Armand Colin, 1986.

Gray, J. and Y. Pesqueux. 1993. Evolutions actuelles des systèmes de tableaux de bord. Comparaison des pratiques de quelques multinationales américaines et françaises. Revue française de comptabilité 242: 61-70.

Hacking, I. 1983. Representing and intervening. an introductory topic in the philosophy of natural science. Cambridge: Cambridge University Press.

Hacking, I. 2004. Est-ce qu'on voit à travers un microscope?. In Philosophie des sciences, eds. S. Laugier and P. Wagner, 238-274. Paris: Vrin.

Kuisel, R. 1984. Le capitalisme et l'Etat en France. Paris:Gallimard.

Lauzel, P. and A. Cibert. 1962. Des ratios au tableau de bord, $2^{\text {nd }}$ ed. Paris: Editions de l'entreprise moderne.

Lebas, M. 1996. Management accounting practice in France. In Management accounting: european perspectives, ed. A. Bhimani, 74-99. Oxford: Oxford University Press.

Levy-Leboyer, M. 1980. The large corporation in France. In Managerial hierarchies. comparative perspectives on the rise of modern industrial enterprise, eds. A.D. Chandler and H. Daems, 117-160. Harvard: Harvard University Press.

Malo, J.L. 1995. Les tableaux de bord comme signes d'une gestion et d'une comptabilité à la française. In: Mélanges en l'honneur du professeur Claude Perochon, 357-376 Paris: Foucher.

Nikitin, M. 1989. La naissance de la comptabilité industrielle en France. Unpublished $\mathrm{PhD}$ thesis, University of Paris Dauphine.

Norman, D.A. 1991. Cognitive artifacts. In Designing interaction - psychology at the human-computer interface, ed. J.M. Carroll. Cambridge: Cambridge University Press. Translation used in the original paper: Les artefacts cognitifs. Raisons Pratiques 4 (1993): 15-34.

Public Histoire 1991. L'identité d'un groupe. Lafarge-Coppée 1947-1989. Paris: LafargeCoppée.

Satet, R. 1936. Le contrôle budgétaire, prévisions commerciales, industrielles et comptables, pour la direction rationnelle des affaires. Paris: Dunod.

Satet, R. and C. Voraz. 1946. Les graphiques, moyen de direction des entreprises. $6^{\text {th }}$ ed. Tourcoing: Editions Georges Frère.

Yates, J. 1989. Control through communication. The rise of system in American management. Baltimore: The Johns Hopkins University Press.

Zan L. 1994. Toward a history of accounting histories. Perspectives from the Italian tradition. The European Accounting Review 3, no. 2: 255-307. 
Figure 1. Tableau de bord of the Managing Director of Lafarge in 1963: deliveries of all products per factory.

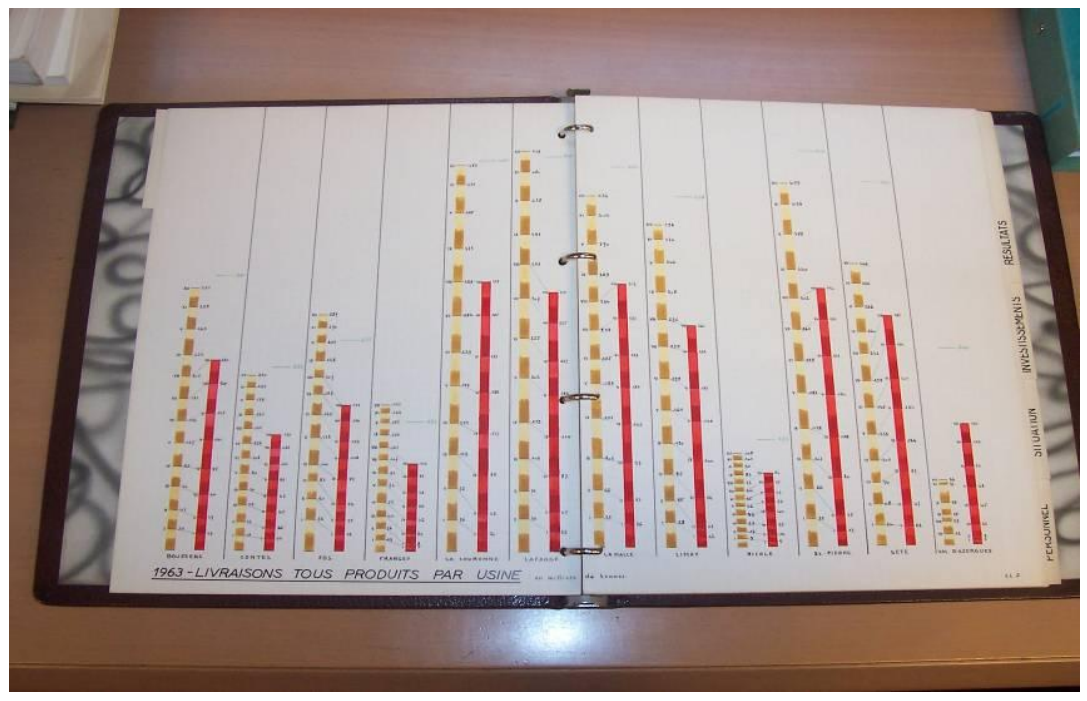

Source: Lafarge Archives. 
Figure 2. Tableau de bord of the Managing Director of Lafarge in 1963: details of the unionisation of the personnel

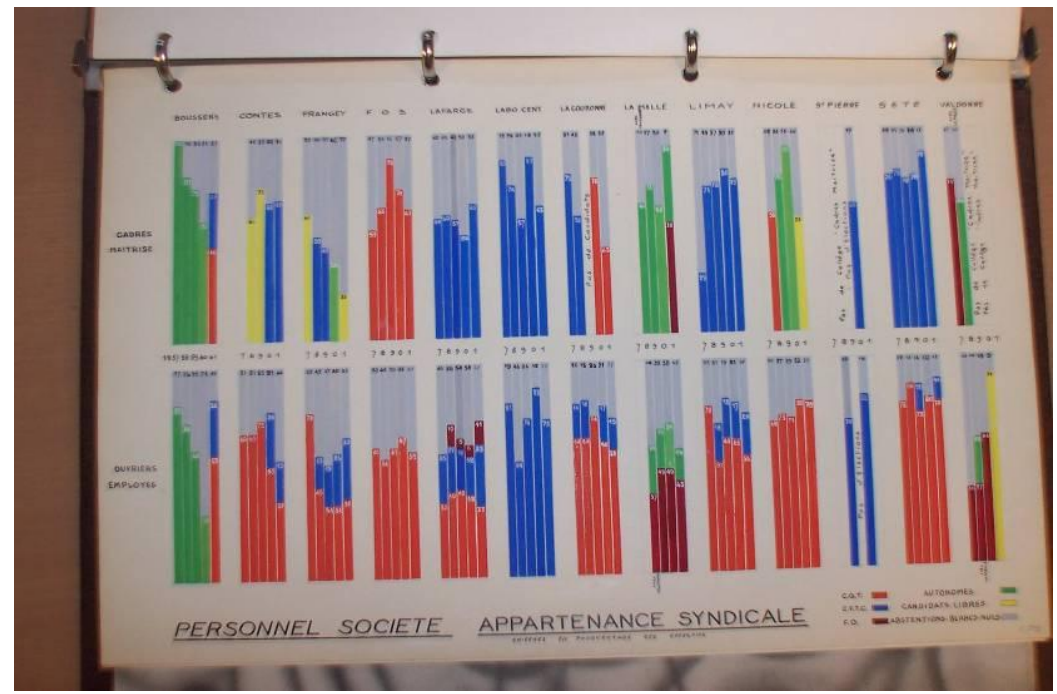

Source: Lafarge Archives. 